as different as those of Charles Coulson (the theoretical chemist who became Rouse Ball Professor of Applied Mathematics at Oxford) and Ian Ramsey (who became Nolloth Professor of the Philosophy of Religion at Oxford and later Bishop of Durham). Dr Dillistone's biography is opportune because the conservative, intellectually uncritical kind of Christianity from which Raven released so many, is today attractive in its simplistic unambiguity to many of the young who can scarcely hear any other voice. "Raven, thou shouldst be living at this hour", but, failing that, we can again catch those rich and profound cadences through his faithful biographer.

But Dr Dillistone is no adulatory sycophant. He shows us where this idol had feet of clay : his failure to understand the crises of continental thought under the impact of the Nazis; his overmagisterial non-suffering impatience with 'fools'; his too-rapid dismissal of any dialectical, non-unified system of thought; his almost pathological concern with his supposed rejection by "the Establishment" of his day on account (he supposed) of his unpopular pacifist views and of his support for the ordination of women.
More positively, Dr Dillistone has dug deeply to discover accounts of Raven's moments of illumination which carried him through the devastating experiences at the Front in the first World War and through tragic bereavements at critical moments in his life. The inner life of the Regius Professor, the Master of a Cambridge college and the Vice-Chancellor of that university, are gently, surely and shrewdly unveiled for us in a way which shows how what Raven loved to call "the sublime law of sacrifice" (quoting Fabre) lay behind the public image.

Those of us who have known Raven through his writings can, with the help of Dr Dillistone, now meet him as the complex, exceptionally gifted and contradictory man he was. Even more important, those who have known neither him or his writings can, through this sympathetic biography, now be inducted into the thought of a man who combined enthusiasm for science with insight into religious experience into a unique amalgam so clearly needed by our disrupted and fissiparous culture. For Raven, in both spheres, the exploration was liberal and open-ended and productive of that unity of vision shared, across the centuries, with Ray.

\section{Not whole but just some of the parts}

Microbial Communities in a ForestRendzina Ecosystem: The Pattern of Microbial Communities. By I. M. Szabo. Pp. 415. (Akademiai Kiado; Budapest, 1974.) $£ 10.50$.

THE microbial ecology of soil is a subject which has in the last few years acquired a voluminous literature at an ever increasing rate. Unfortunately, this has been achieved without any comparable increase in the understanding of the systems under study. The diversity of microbial communities, their functions and their microhabitats have obscured all attempts to derive any but the most basic ecological generalisations. Professor Szabo attributes this failure, in part, to a dispersal and dilution of research effort. In spite of the complex nature of the system (or perhaps because of it) research planning has tended to concentrate on specific functions, organism groups, or ecological parameters. This has resulted in a science in which there is considerable knowledge of some of the parts but little understanding of the whole.

The philosophy of the studies reported in this volume is different. For over 15 years Professor Szabo and his colleagues have conducted an intensive study of soil microflora and fauna in a single area of oak-hornbeam forest in western Hungary. The concentration on a single site is deliberate. Only in that way can "those general principles which govern the activities of complex saprophytic communities in the soil" be recognised and understood. It is in that context that the reader is asked to judge the contents of this book.

The first chapter describes features of the forest site at the ecosystem level; in Chapter Two the focus becomes finer and we are given accounts of micromorphological studies, the utilisation of techniques of soil sectioning and electron microscopy, and the distribution of microbial communities and their microhabitats. The third chapter gives an account of the distribution of soil animals and microorganisms in relation to the conditions of moisture and temperature in the soil.

It is not until Chapter Four, however, that the main subject of this book is encountered: the structure and species composition of the microbial communities occupying selected habitats of the forest-rendzina soil. A discussion of the current status of the species-concept in the Actinomycetes leads on to a consideration of the techniques of multiple character testing and numerical similarity analysis by which Professor Szabo defines the members of his microflora. In this chapter 34 speciesgroups from the A horizon of the soil are described using those methods; the description is supported by many pages of tabulation of characteristics and by a discussion of the validity of the status of the species groups in comparison with the conclusions of other workers. In the succeeding two chapters this process is repeated for the actinomycete and bacterial floras of other habitats, notably the gut and faecal communities of the larvae of Bibio marci, an important component of the fauna active in soil decomposition, and the rhizoplane community of Robinia pseudoacacia. These three chapters comprise two thirds of the total text; they are almost wholly devoted to the reporting and discussion of the taxonomic studies. This gives a highly specialised character to the book that seems out of keeping with the drift of the early chapters and the stated aim.

The interest of the same readers may, however, be reclaimed by the contents of the last chapter. Here, there is an enormously stimulating discussion ranging over many aspects of the structure and functioning of the microbial communities of soil, including such topics as microbial successions, the role of microbes in soil humification and fertility, the dissemination of soil microbes, and the maintenance of the genetic diversity of soil populations. Here also the ecological implications of the work described in the three main chapters is allowed to struggle free of its taxonomic clothing and to be seen in a wider ecological context.

I was left with a strange impression that I had read two books in one. Anyone with an interest in the microbial ecology of the soil who can gain access to the book will find much to stimulate him in the early chapters and in Chapter Seven. Whether they will find it worth paying the expensive price for the sake of the specialised remainder will depend on their own particular interests. A number of reservations must also be recorded. I found it difficult to be convinced by much of the experimental work in Chapter Three; for instance the relevance of survival testing of microbes over the temperature range $35-65^{\circ} \mathrm{C}$ is obscure when related to their activity in a forest soil of temperate climate-particularly when no suggestion is made of potential thermophilic phases. The lack of detail in the reports of the quantitative ecological data contrasts strongly with the admirably complete treatment of the taxonomic data and detracts from the impact of the topics discussed in Chapter Seven.

Nevertheless, this well-produced book remains an important contribution to the literature, partly to the specialised field it serves but more generally because of the opportunity it affords for an appraisal of the Szabo philosophy of "intensive, single-site study".

Mike Swift 